\title{
BIOMONITORING OF INLAND AND INSHORE WATERS WITH USE OF DREISSENA POLYMORPHA MUSSELS
}

Piotr Matuszak ${ }^{1}$,, Grzegorz Grodzicki ${ }^{1)}$, Tomasz Jankowski ${ }^{2}$, Paweł Matlakiewicz ${ }^{4)}$

1) Bionitec Sp. z o.o., 87-100 Toruń

2) The Department of Biology and Environment Protection of Nicolaus Copernicus University in Toruń, Poland

${ }^{3)}$ The NCU Centre for Technology Transfer, Toruń, Poland

\section{ABSTRACT}

The pollution of water that is used for consumption and in agricultural holdings contributes to an increased mortality rate, inhibition of growth and physiological functions, changes in the DNA (genotoxicity), changes within tissues (cytotoxicity) and organs of individuals who are exposed to chemical components. One of the most dangerous toxin classes which have effect on animals and humans who come into contact with contaminated water is the class of cyanobacterial toxins released by dying cyanobacteria. They contribute to very serious health conditions and also to fatalities. Toxins of this type are relatively difficult to detect on account of their seasonal changeability in blooming. One of the most effective methods of detecting water contamination automatically and continuously is biomonitoring with the use of Dreissena polymorpha mussels.

Key words: biomonitoring, mussels, Dreissena polymorpha, cyanobacterial toxins, biogenic elements, eutrophication.

ARTICLE INFO

PolHypRes 2015 Vol. 52 Issue 3 pp. 49-58

ISSN: $1734-7009$ elSSN: 2084-0535

Rewiev article

DOI: 10.1515/phr-2015-0016

Pages: 10, figures: 0 , tables: 0

Delivery date: $05.07 .2015 \mathrm{r}$.

page www of the periodical: www.phr.net.pl

Date of approval for print: $15.07 .2015 r$

Publisher

Polish Hyperbaric Medicine and Technology Society 


\section{INTRODUCTION}

Research conducted by many research groups over the last thirty years has shown increasingly clearly the importance of the clarity of water, not only for consumption, but also water used in agricultural holdings (e.g. for watering animals) or naturally circulating in the environment. It has been proved that the impact of the contamination on living organisms, including humans stems from the interaction between the pollutant and the organism, population or biocenosis.

This is reflected in an increased mortality rate, inhibition and disorders of growth and physiological functions, changes in the DNA (genotoxicity), changes within tissues (cytotoxicity) and organs of individuals who are exposed to chemical components [1]. Since the principle of sustainable development in Poland (like in an increasing number of other countries) became elevated to the constitutional rank (in accordance with Article 5 of the Polish Constitution), the manner of social and economic development that integrates political, social and economic activities should be in accordance with natural balance and sustainability of basic natural processes. According to the report of the Foundation of Energy for Europe, Poland is among the countries with relatively scarce water resources [2].

In the 'Population and Environment' international programme conducted in 1993, Polish water resources were ranked $72^{\text {nd }}$ out of 100 analysed world countries. Among European countries it is Poland that is endangered with water deficiency the most. Polish resources are about $1580 \mathrm{~m}^{3}$ mper capita a year, with the accepted threshold of renewable water resources in the world being $1700 \mathrm{~m}^{3}$ per capita a year. The average level in Europe amounts to $4500 \mathrm{~m}^{3}$ per capita a year. In the time of the most severe droughts, water resources in Poland may drop beneath $1000 \mathrm{~m}^{3}$ per capita a year.

A growing concern for the environment and particularly its potential threats are reflected by growing financial contributions intended for activities that identify the abovementioned threats and prevention. According to the report prepared by the researchers of the Department of Chemistry and Biochemistry from the Office of Technology Commercialisation of the University of Texas in Austin, USA, the market for biological substances and chemicals detection was estimated at 2.3 billion USD in 2002 , and 4 billion USD in 2007. On the other hand, the market for detecting environmental threats in 2003 was estimated at 3.4 billion USD and the figure is increasing.

The abovementioned data proves that the pursuit of effective methods of detecting and preventing environmental threats is a key issue. On the other hand, as mentioned before, many of them are not used on a larger scale as they are not economically justified. It is hard to imagine that all the water intakes in Poland could be tested at least once an hour (the number of 'large' intakes with the annual consumption of $800000 \mathrm{~m}^{3}$ alone is 258, whereas the number of registered intakes is 5500 , according to the Polish Hydrogeological Survey [3].

The situation of Polish lakes is quite dramatic. According to the study of prof. Adam Choiński, there are 7081 lakes with an area of over 1 ha, which ranks Poland among countries with a low lake density index [4]. Hence losing any one of them (eutrophication, over-fertilization, overgrowing and transformation into marshes) is a severe blow dealt to the national and social wealth, especially in the context of being legacy for the future generations. It affects the country's climate, water management, balance of species, country's tourism, and general health of the society. The scale of the phenomenon is reflected by the fact that over the time span of 40 years (1954-1992) as many as 2215 lakes disappeared, which constitutes $11.22 \%$ of the entire area of lakes of that time (data from the catalogue of Polish lakes in 1954 and 1992 by prof. A. Choiński).

The process of disappearance of small lakes up to 5 ha, which constitute $44 \%$ of lakes in Poland, is the most dynamic. It needs to be emphasised that lakes are the significant link in the circulation and retention of water in balanced basins, whereas the contamination of water in the system of changes that are taking place in present time is reflected by its eutrophication. We are dealing here with the inflow of substances that fertilise water, as well as toxic agents.

Accumulation of pollutants is a complex and long lasting process which may pass unnoticed for years. It is chiefly related to the concentration of pollutants in bottom sediments and deeper parts of lake basins, whereas their intensity and significance (as a result of progressing eutrophication) is usually reflected by the number of disappearing fish species. Restoring balance is a time consuming and expensive process; however very important if the future generations are to inherit environment in good condition and subjected to anthropogenic pressure in the least degree. It is common knowledge that needs to be kept in mind that expenses incurred for prevention are many times lower than those related to reverting the undesirable phenomena.

This is why the role of effective and common methods of monitoring environment, including standing and running waters, is so important. These methods indubitably include systems based on biosensors which are cost effective and characterised by a wide spectrum of applications, and may be used in real time without interruptions.

\section{THE OCCURRENCE AND DETERMINATION OF POLLUTANTS}

The effect of pollutants may be divided into two categories depending on their impact range. Pollutants from point sources are relatively easy to identify and classify (type of the pollution, its concentration, a total amount released to the environment in a given time, etc.).

They usually come from discharges of industrial and urban waste, effluence from landfills of industrial, urban and dangerous waste, sometimes they appear temporarily (e.g. as a consequence of an accident, failure of transport routes, deliberate discharge of hazardous waste to environment).

On the other hand, pollutants from area sources, which spread over vast areas or bodies of water are difficult to identify, classify and prevent (including neutralisation and securing). They usually originate in agricultural effluence, contaminated soil and urban areas, as well as bottom sediments, dry and wet atmospheric deposition, etc. Pollutants from area sources in many cases constitute a mixture of substances whose toxicity is very difficult to determine (on account of the differences in quantitative proportions of components and the amount of emissions that is difficult to determine).

Furthermore, many of the pollutants from area 
sources (in contrast to those from point sources, which are more intense) cause the transfer of substances whose concentrations become hazardous to living organisms only after a long-term exposure, whereas their temporary presence passes unnoticed. Besides, their distribution over a larger area causes the point detection to decline with a possible long accumulation inside organisms at the same time. Therefore, pollutants from area sources are the main cause for condition of individual organs, especially among adult population.

They also lead to genotoxicity which is reflected by mutations that are more often than not transferred to future generations, which may cause significant phenotypic changes if given enough time. Mutations relate to genetic changes in somatic or germ cells. Mutations in somatic cells may contribute to various defects that may lead to the formation of neoplasms, whereas mutations in germ cells may cause genetic diseases in future generations. In so far as the relationship between being exposed to each individual substance and carcinogenesis in people is well documented, similar relationships for hereditary defects are difficult to prove [1].

Nevertheless, exposure of living organisms to long-term effects of different substances is not only toxic, but also teratogenic and genotoxic, as the scope of contamination and their persistence may be high enough for the effects to appear, given a sufficiently long time [5].

One of the major threats are the cyanobacterial blooms and the cyanobacterial toxins that they release in bodies of water subject to eutrophication (lakes, ponds, dam reservoirs) and coastal waters, which are hazardous to human health and life. Among cyanobacterial toxins one may distinguish neurotoxins (anatoxin-a, anatoxin$\mathrm{a}(\mathrm{s})$, saxitoxin and neosaxitoxin), carcinogenic (e.g. microcystins, lipopolysaccharides), dermatoxins (e.g. lyngbyatoxin-a, aplysiatoxin and lipopolysacharides), hepatotoxins (microcystins, nodularins and cylindrospermopsin), and many others [6].

The most frequently occurring toxin is the hepatotoxin called microcystin. Currently, over 70 different structures of these compounds are known. Hepatotoxins, which include microcystins and nodularins are responsible for poisoning animals and humans that have come into contact with toxic blooms. They are characterised by high durability in aquatic environment on account of its chemical structure. What is more, neurotoxins (anatoxins and saxitoxins), on account of their low lethal dose value belong to the strongest natural toxins. The presence of the neurotoxic amino acid BMAA ( $B-\mathrm{N}$-methylamino-L-alanine) may be strictly related to the incidence of Alzheimer's disease recorded in Canada [7].

Determination of water with chemical or physical methods, apart from being cost-inducing, has several other properties which significantly limits their application as elements of permanent environmental supervision. One of them is the necessity to run most of the tests in a laboratory that is equipped with proper reagents and a testing apparatus. Another one is related to the time that passes between the moment of collecting a sample and the moment of obtaining results (the time required to collect samples and transportation have also been included).

However, one of the most important features is the necessity of an early determination of the threat that a given test concerns. Does it consist in determining a particular species of the bacteria, an element or a toxin. There is a high probability that in the case of a given series of tests, the factors that were not considered before and later overlooked during the selection of the test method, will remain unnoticed. This property is practically nonexistent with the application of live bioindicators, characterised by an appropriate sensitivity spectrum. If any substance or a biotic factor unfavourably affect a given testing organism, an appropriate reaction to adverse factors will ensue (including death) regardless of whether or not the researcher anticipated the occurrence of given stimuli (e.g. poisons).

Hence biomonitoring methods are more universal than other physical-chemical laboratory approaches (even though the latter are much more accurate and indispensable in the processes of precise threat identification). It should be stressed that seasonal changeability of phytoplankton, which is a good indicator of early eutrophication causes the evaluation of a body of water in terms of over-fertilization to be difficult [8]. Phytoplankton, like phytobenthos, collects biogenic elements straight from midwater. Next, its part is filtered by filter feeders, which also include mussels. Hence indication methods that are based on these molluscs may reliably inform about threats of early eutrophication.

\section{BIOMONITORING}

Bionitec Sp. z o.o was established almost a year ago on the initiative of the Centre for Technology Transfer and a team of initiators, the mention of which can be found in the article entitled 'Results of the commercialisation of scientific research in the light of experience gained at the Nicolaus Copernicus University Centre for Technology Transfer' published in the present issue of the magazine.

The main idea behind using Dreissena polymorpha mussels (Zebra mussel) together with the classification of observable practices in molluscs comes from prof. Ryszard Wiśniewski, a hydrologist famous in Poland and abroad, a long-term employee of Nicolaus Copernicus University. The idea of using living organisms, including mussels, for monitoring the surrounding environment is not new. Many of the solutions were created dozens of years ago.

However, most of them did not go beyond limiting technology of the time and today offer only a basic functionality. It consists in measuring the opening angle of the shell and making conclusions about the condition of the surroundings based on this measurement. In its basic version, the measuring system is composed of a set of mussels which are permanently attached to prepared substrate.

The Zebra mussel is a sedentary species which is not disturbed by permanent immobility. These molluscs very often settle on their kin forming vast colonies. The organisms form structures so dense that most of them are literally forced to remain in place. The mussel feeds by taking in water through the incurrent siphon catching particles of food and releasing water through the excurrent siphon. The matter that the mollusc deems nutritious is digested and absorbed, whereas the particles that are unfit for consumption are lumped (pseudofaeces) and excreted together with water.

As a by-product of this process, water is filtered of its suspension made up of particles so small as to float in midwater for a long time. The phenomenon of rising matter is particularly noticeable in the so-called 
resuspension layer, i.e. the area of highly hydrated sediment adjoining directly to the bottom of a body of water subject to eutrophication. Particles of the suspension are bound together into bigger lumps through the activity of filter feeders (filtering organisms), which then settle into the bottom more easily and concentrate into the substrate of higher density than the resuspension layer. In the case of mussels filtration is accompanied by contractions of shell constrictors which are reflected in the movement of both valves.

For biomonitoring an apparatus that measures the opening angle is placed on the valve or valves, which allows to record the changes and dynamics of the opening in time. In older constructions a system of metal rods was used in order to change the resistance of the active element. Contemporary methods involve the use of magnet - hall effect sensor system which can measure the changes in field strength with high precision and resolution in wide range.

What is more, the construction of this type is resistant to factors that are present in bodies of water and have a relatively low temperature dependence (most systems carry out temperature compensation independently). The mussel reacts to the chemical composition of the floating matter as it takes it in. Since Dreissena is an eurytopic species it is capable of surviving in most adverse conditions, including in highly contaminated water environment.

On the other hand it is very sensitive to the composition of the absorbed food, which enables the application of their reactions in biomonitoring. Both mentioned facts make Dreissena a useful and universal bioindicator. Eurytopicity ensures a wide range of concentrations and harmful substances detected by molluscs. On the other hand, nutrition sensitivity enables a reaction even to low concentrations of harmful substances. It is significant for one more reason.

Due to typical reactions of a mollusc it is possible to detect the class of substances a given pollutant belongs to and the concentration class in which it occurred. It is clear that the mussel is not a physical-chemical sensor and as such may not give an answer that would be comparable to a laboratory, or even a field test. Nevertheless, biomonitoring has two basic advantages.

Firstly, it is universal. If the physical-chemical sensor has not been designed to detect a particular substance, it will not react to it while operating. A living organism was designed by nature, therefore it will react to anything that will harm it. As a rule, whatever is harmful to molluscs is also harmful to humans; however, the concentrations detected by mussels are low enough for the mollusc reactions to be interpreted as a potential threat, and not contamination. Secondly, mussels are capable of functioning continually and are easy to obtain.

A set of physical-chemical sensors that would be similarly universal and sensitive and work continuously is expensive beyond any comparison, not to mention maintenance costs and risk of theft (mussels, contrary to measuring equipment are not desirable for scrap metal gatherers and the station may only be damaged through the robber's ignorance).

Importantly, mussels are complex enough (as compared with bacteria) to possess an entire array of specific reactions which enables the determination of substance classes and their concentrations, and on the other hand simple enough (as compared with fish) to be able to function without the man's surveillance.

\section{COMMERCIALISATION OF TEST RESULTS}

As mentioned before using mussel reaction for determining the clarity of water is not a new idea. They are used in selected water intake facilities, purification plants, rivers and lakes. Nevertheless, a vast majority of these solutions work on a two-state basis by either pointing to the lack of threat or presence thereof. In the former case individual mussels keep their shells apart in different degrees and move them, which is a typical behaviour for their life activity. However, when all, or nearly all mussels are closed, the situation is interpreted as a threat (stress in mussels). The worst possible scenario consists in keeping the shells wide apart and no movement in all or most of the mussels. This situation indicates that the molluscs have died, in all likelihood, as a result of high water contamination, which is lethal also to humans.

The creators of biomonitoring solutions sometimes add mixed states, which consist in informing about a potential but not yet defined threat if most mussels close their shells. The problem is that mussels are prone to all sorts of stress factors, not necessarily chemical. Some examples include motor-car induced noise, human activity, or the sound of oars swatting the surface of the water. Mussels are also sensitive to violent changes in lighting, temperature, fluctuations in $\mathrm{pH}$, and many other stimuli.

Hence two-state biomonitoring is equivocal and frequently erroneous (false alarms). The idea of the founders of Bionitec steers away from the approach described above. Firstly, a colony of mussels that is numerous enough needs to be ensured, so that their reactions are statistically significant. Besides there is always a certain number of mussels that die off naturally, but it should not be a factor of great importance as long as it is a relatively small group.

Many of the solutions implemented so far involved the use of 8-10 mussels. For comparison, the Biomitec equipment includes at least 50. Secondly, the approach to the recorded data is different. The first step is taken in an adequately equipped laboratory where tests are performed on group of mussels that is numerous enough (about 1000 mussels) to check their reaction to all individual chemical factors, other physical factors, and no stimuli whatsoever.

The recorded time series are then subjected to filtering and an advanced data analysis. The methods that are used include DWT (Discrete Wavelet Transform) and kNN classifiers (k-Nearest Neighbours), SRDA (Spectral Regression Discriminant Analysis) and FDA (Fisher Discriminant Analysis). This approach was first successfully applied by the team of R. Wiśniewski, P. Przymus and K. Rykaczewski [9] [10].

Because a large amount of data was recorded, the techniques of processing big data in real time were used in the solution, which made use of GPGPU specialised computing processors (architecture employed in the world's most powerful computers). The detected patterns are the indicators that define the most likely type of contamination, as well as the class of its intensity (the details are later determined as a result of a toxicological laboratory test).

When a threat is detected a message or alarm information is sent to all the authorised people or authorities. The solution may also make autonomous decisions to a temporarily cut off the drinking water intake (the functionality is determined while the commission is being carried out). An interesting extension has also been 
provided which consists in the possibility to follow the biosensor activity on the website of the manager of the body of water or the field institution (e.g. commune office, district office, voivodeship office or Marshall's office).

The information is displayed by means of a graphic plug that demonstrates the results of the currently held signal analyses (the results are taken straight from the centre of analyses). The research results were later commercialised by Bionitec Sp. $\mathrm{z}$ o.o. which is also the owner of the patent application No. 409697. First products of the new line will be launched in mid-2016.

\title{
BIBLIOGRAPHY
}

1. Traczewska TM. Biological methods of evaluating environmental contamination. Publ. 1 Wrocław: OWPW; 2011: 19-21, 15-17) ISBN 978-83-7493-597-5.

2. Giedrys K, Kądzielawski G, Krasnowska K, Krawczyk J, Purski P, Szymczakowska E, et al. Water - a burning problem. Warsaw. The Energy for Europe Foundation, http://fede.org.pl/wp-content/uploads/2013/01/raport-07.pdf [quoted 2013-01].

3. Frankowski Z, Gałkowski P, Mitrega J. The structure of groundwater intake in Poland. Publ. 1 Warsaw PIG: 2009: pp.162; ISBN 978-83-7538-450-5.

4. Choiński A. A catalogue of Polish Lakes. Publ. 1 Poznań: WN UAM; 2006; ISBN 83-232-1732-7.

5. Miller WE, Petreson SA, Greene JC, Callahan CA. Comparative toxicology laboratory organism for assessing hazardous waste sites. Environ Quality 1985; 14(4):569-574.

6. IInicki P Causes The causes, sources and the course of surface water eutrophication. Przeglad Komunalny 2002; 2:35-49.

7. Błaszczyk A, Mazur-Marzec H. BMAA and other neurotoxins of cyanobacteria. Polish Hyperbaric Research. 2006; 4(17):7-14

8. Soszka H. Methodological problems related to the evaluation of eutrophication level in lakes for the purposes of designating nitrate vulnerable zones Woda-Środowisko-Obszary Wiejskie 2009; vol. 9 z. 1 (25):151-159.

9. Przymus P, Rykaczewski K., Wiśniewski R. Zebra mussels' behaviour detection, extraction and classification using wavelets and kernel methods. Future Generation Computer Systems 2014; 33:81-89.

10. Przymus P, Rykaczewski K, Wiśniewski R. Application of Wavelets and Kernel Methods to Detection and Extraction of Behaviours of Freshwater Mussels Future Generation Information Technology. Third International Conference, FGIT 2011 in Conjunction with GDC 2011 Jeju Island, Korea, December 8-10, 2011 Proceedings. 1th edition Berlin Heidelberg: Springer-Verlag, 2011. 43-54 ISBN: 978-3-642-27141-0.

\author{
mgr Piotr Matuszak \\ Bionitec Sp. z 0.0., \\ ul. Gagarina 5 \\ 87-100 Toruń, \\ e-mail: piotr.matuszak@bionitec.pl
}

